\title{
Effect of mineral additives to a gypsum wet deformation
}

\author{
Andrii Plugin ${ }^{1, *}$, Artem Iefimenko ${ }^{1}$, Olga Borziak $^{1}$, Edwin Gevorkyan ${ }^{1}$, and Olena Kaliuzhna ${ }^{1}$ \\ ${ }^{1}$ Ukrainian State University of Railway Transport, Feuerbach sq. 7, 61050 Kharkiv, Ukraine
}

\begin{abstract}
The influence of mineral additive, i.e. ground granulated blast-furnace slag on artificial gypsum stone humidity strains has been studied. The slag content was varied in the range from 0 to 0.33 by weight based on the total amount of the mixture. The measurements were carried out on prism samples with dimensions of $160 \times 40 \times 40$ $\mathrm{mm}$. The samples were placed vertically in containers with water, the deformations were measured using dial indicators. It was established that the humidity strain value depends on the content of the granulated milled blastfurnace slag. A maximum strain of over $0.001 \mathrm{~m} / \mathrm{m}$ is observed for the gypsum stone without mineral additive. A relative strain is decreased with an increase in the slag content. Minimum humidity strain of $0.0003-0.0004 \mathrm{~m} / \mathrm{m}$ was observed for the artificial gypsum stone with the relative slag content of 0.05-0.1 and more than 0.27 . This fact confirms our assumption that the water concentrated in the contacts between the individual crystals and particles of the structure of gypsum stone has a wedging effect that contributes to a low water resistance of gypsum. The values of the humidity strains of the artificial gypsum stone are suggested for the use as additional indicators of its water resistance.
\end{abstract}

\section{Introduction}

Gypsum binder-based materials are characterized by the ecological safety, sufficient strength and durability and also by a low weight and relatively low heat and sound conductivity. Due to these advantages, gypsum materials are widely used for construction purposes. However, their insufficient water resistance that results in an essential loss of strength in the case of their water saturation and/or wetting restricts the fields of their broad application. A low water resistance of gypsum materials is mainly explained by the calcium dihydrate solubility and the wedging forces that are created by the water that penetrates into the pores.

As of today, many methods are available that can increase the gypsum water resistance, in particular a decrease in the water-to-gypsum ratio, an addition of polymer additives, impregnation and hydrophobization of the surfaces of gypsum stone, combination with hydraulic binders, addition of active mineral additives and additives-microfillers that contribute to the formation of the dense structure of gypsum stone. During the studies carried out to improve the compositions of gypsum binder the water resistance was evaluated by the softening factor, i.e. the compression strength ratio in the water saturated state and initial dry state.

Nevertheless, the contribution made to the water resistance of gypsum stone by abovementioned wedging forces that are created by the water that penetrates into the pores requires additional studies. However, it is known to us that these forces simultaneously result in the humidity strains of the artificial stone. Hence, the studies of the volumetric strains of the artificial gypsum stone with mineral additives and their relations with the water resistance are an important task.

\section{Analytical review of literature sources}

A low water resistance of gypsum items is explained by a rather high solubility of gypsum dihydrate equal to 2.04 $\mathrm{g} / 1$ [1]. In addition, the water that penetrates into intercrystalline cavities is adsorbed by hard surfaces and the wedging pressure is created between them that disrupts local contacts between the crystals. An assumption can be made that these reasons are interrelating and enhance each other.

Gypsum modifications are described in many research papers [2-6], etc. The water resistance of gypsum binders can be increased by a decrease in the water-to-gypsum ratio, by combination with hydraulic binders [4-6] and by addition of mineral additives-fillers [7-12], hydrophobization additives [12], polymers and the fiber [13]. The authors give different explanations to the reasons that contribute to the improvement of the properties. The complex mineral additive that includes the granulated milled blast-furnace slag, fly ash and pazzolana (zeolite) provides the densification of the structure of the cement stone and an increase in its strength, according to [15]. In [16], the internal strain of the artificial stone can be controlled through the addition of the slag-lime binder to the Portland-cement clinker. To improve physical and mechanical characteristics, the authors [17] modify binding substances by clay fillers. The electrolytes, especially in the form of the complex additive, provide an increase in the water impermeability

\footnotetext{
* Corresponding author: aaplugin@gmail.com
} 
[18] and strength [19] of cement composites. In [19], such an influence of potassium and sodium sulfates and carbonates is explained by the modification of the microstructure and porous structure.

The structure and the properties of gypsum materials can also be controlled through the addition of mineral fillers and other binders of a different composition and dispersion degree [4-13; 20-22]. The most stable compositions of gypsum binders are gypsum-cementpazzolana binders [1]. Among their hydration products are not only calcium dihydrate sulfate crystals but also low-basic calcium hydrosilicates and other slightly soluble hydrates. According to [14], these can form electroheterogeneous contacts with calcium dihydrate sulfate crystals that provide the formation of the waterresistant structure.

In [4], the water resistance of gypsum made of waste is attained by mixing it with the fly ash and Portland cement. The authors [21] add mineral and organic modifiers to gypsum and explain their action by the enhancement at the atomic and molecular level. In [20], the industrial waste that contains calcium dihydrate sulfate is used as a substituent of natural gypsum. In order to form a denser structure of gypsum stone, the authors [22] use the methods of the computer simulation of the composition of the raw mixture and in [2] they substantiate an optimal proportion that provides a maximum strength for the mixed binder made of slag, gypsum and clinker. In $[5,7,10,13]$, consideration is given to the microreinforcing action of mineral additives on gypsum stone and its effect on the strength. An addition of $14 \%$ of the ultra-dispersed zeolite to gypsum resulted in an increase of its water resistance from 0.31 to 0.84 [7]. An analogous effect [10] caused by the addition of zeolite and carboxylate is also explained by an essential change in the structure. In [13], an increase in the gypsum strength is explained by the effect of the dispersed reinforcement.

The effect of mineral and chemical additives on the gypsum water resistance was studied in $[4 ; 7 ; 8 ; 11 ; 12]$. The authors [8] modify gypsum by the metallurgy dust and multi-walled carbon nanotubes. They explain an observed increase in the water resistance by the formation of amorphous hydrosilicate structures on the gypsum crystal surface that bind gypsum crystals and prevent an access of water to them. In [9], gypsum is modified by the ultradispersed metallurgy dust and anhydride. The authors note a change in the morphology that results in the densification and an increased strength and water resistance. In [11], the authors state an intensification of the hydration and the formation of a denser structure due to the addition of the complex chemical additive. Microand nanoadditives of silicon carbide $\mathrm{SiC}$ that act as crystallization centers and result in the formation of larger crystals also intensify hydration and structure formation processes [12].

It is known [18] that the properties of the materials that are based on inorganic binders are conditioned by the availability of the electrostatic interaction of the double electric layers of structural elements. The strength and the water resistance of hydraulic binders are defined by strong electroheterogeneous contacts between the particles with opposite surface charges. Air-setting binders consist of the elements that have similar charges, therefore their strength and water resistance are defined by electrohomogeneous contacts with the intermolecular interaction. In [3], a hypothesis was put forward and it was proved that maximum possible physical and mechanical parameters of the cured mineral binders can be attained due to the equality between themselves of the total areas of particle surfaces of a dispersed phase in the volume unit that have opposite surface charges. We believe that such equality can be attained through the composition control of the hydration products of the binder and the embedment of highly-dispersed inert particles into their structure. The gypsum stone strength is mainly defined by electrohomogeneous contacts between the gypsum crystallohydrates with a weak intermolecular interaction. These contacts are destroyed even by insignificant strains $[3 ; 14]$. To provide an appropriate water resistance and to increase the strength of gypsum binders the research papers $[2 ; 14]$ suggest to add mineral additives to their composition that act as the fillers and microfillers with defined surface charges and it will result in the formation of an ample amount of electroheterogeneous contacts with the edges of gypsum crystallohydrates.

It was shown in [18] that the water resistance of gypsum with mineral additives, in particular ground granulated blast-furnace slag depends on the thickness of the interlayers of gypsum dihydrade between the particles of mineral fillers. The thickness of these interlayers is related to the structural characteristic of the filled gypsum stone, i.e. the separation factor of the particles of mineral filler by gypsum dehydrate $\eta$. The dependence of the strength of artificial stone and especially its water resistance [3] has a wavelike or extreme character with the peaks that correspond to the optimal values of separation coefficient $\eta_{\text {opt. }}$ A maximum strength and water resistance are provided in the case of the formation of a denser packing of the gypsum dihydrate crystals in the interlayers between the particles of the mineral filler and in the case of the correspondence of an actual value of the separation coefficient $\eta$ to its optimal value $\eta_{\text {opt }}$. For this purpose, it was suggested in [3] to provide an optimal value of the separation coefficient $\eta_{\text {opt }}$ that is analogous to the optimal separation coefficients of the grains of coarse filler $\eta_{\text {opt }}$ and the fine filler $\eta_{\text {opt }}$ in the concretes. The density of gypsum stone can also be increased through the use of nanodispersed fillers that fill intercrystalline cavities by embedding into the structure and contribute thus to the structure densification $[3 ; 14]$. In this case, the number and the dispersion degree of the fillers are selected to provide the formation of the dense packing of matrix particles in the interlayers between the structure forming parts, in particular gypsum crystallohydrates are supposed to be formed between the slag particles and nanodispersed particles should be formed between gypsum crystallohydrates $[3 ; 14]$. In addition, the nanodispersed particles of the filler can act as crystallization centers increasing thus the dispersion of crystallohydrates and making the structure denser.

Based on the conceptions of the contribution made to a low water resistance by the wedging effect of the water 
concentrated in the contacts between the individual crystals and particles in its structure it was suggested to use a relative linear humidity strain caused by the water saturation (swelling) $\varepsilon_{w}$ in $\mathrm{m} / \mathrm{m}$ as an additional indicator of water resistance.

\section{Research methods and materials}

To carry out experimental investigations we used the gypsum building plaster G-10, ground granulated blastfurnace slag "Zaporizhstal" and the plasticizing additive, i.e. sodium lingosulphonate in the amount of $2 \%$ of the gypsum mass.

The ground granulated blast-furnace slag "Zaporizhstal" had the following parameters: chemical composition, \%: $\mathrm{SiO}_{2}-36.5 ; \mathrm{Fe}_{2} \mathrm{O}_{3}-5.1 ; \mathrm{Al}_{2} \mathrm{O}_{3}-6.7$; $\mathrm{CaO}-46.5 ; \mathrm{MgO}-5.9 ; \mathrm{SO}_{3}-4.2$; the basicity module 1.19 ; the true density $-2810 \mathrm{~kg} / \mathrm{m}^{3}$; the specific surface $3000 \mathrm{~cm}^{2} / \mathrm{g}$; the granulometric composition was defined using the MBI-6 microscope ruler, \%: up to $10 \mu \mathrm{m}-2.5$; for the range of 10 to $23 \mu \mathrm{m}-11 ; 2$ to $36 \mu \mathrm{m}-8.6 ; 36$ to $49 \mu \mathrm{m}-12.9 ; 49$ to $62 \mu \mathrm{m}-8.8 ; 62$ to $75 \mu \mathrm{m}-6.8 ; 75$ to $88 \mu \mathrm{m}-9.2 ; 88$ to $101 \mu \mathrm{m}-6.7 ; 101$ to $14 \mu \mathrm{m}-10.6$; 114 to $127 \mu \mathrm{m}-10.3$; above $127 \mu \mathrm{m}-12.7$. Hence, about $80 \%$ fall to the range of 10 to $130 \mu \mathrm{m}$, and the average particle size is $60 \mu \mathrm{m}$.

The humidity strain was defined using prism-like specimens with the size of $160 \times 40 \times 40 \mathrm{~mm}$ that were cured for at least 7 days and nights and dried in the temperature range of 18 to $22^{\circ} \mathrm{C}$ and the relative humidity of 40 to $60 \%$ to get the constant weight. At least three specimens were used to test each composition. The specimen length $L$ was measured in advance. Each specimen was inserted vertically into the container and the steel or glass plate was laid over it. The indicator of a clock type that was clamped in the laboratory holder (Fig.1) was connected to it and initial indicator readings were recorded.

The container was filled with water to the level of the upper edge of the specimen and the indicator readings were taken every 0.25 to 0.5 hours during first 6 hours. A sight was taken on it for at least 24 hours.

The values of absolute linear humidity strain were measured for each time point $i$ according to the indicator readings $X_{i}$ :

$$
\Delta L_{i}=X_{i}-X_{0}, \mathrm{~mm},
$$

where $X_{0}$ is the initial indicator reading prior to pouring a required amount of water.

A relative humidity strain was measured for each time point:

$$
\varepsilon_{w}=\Delta \mathrm{L}_{i} / \mathrm{L}
$$

Based on $\varepsilon_{w}$ values, the kinetic curve of the dependence of $\varepsilon_{w}$ on time was constructed and using this curve a maximum value of $\varepsilon_{w}$ was defined and the time required to attain it was recorded.

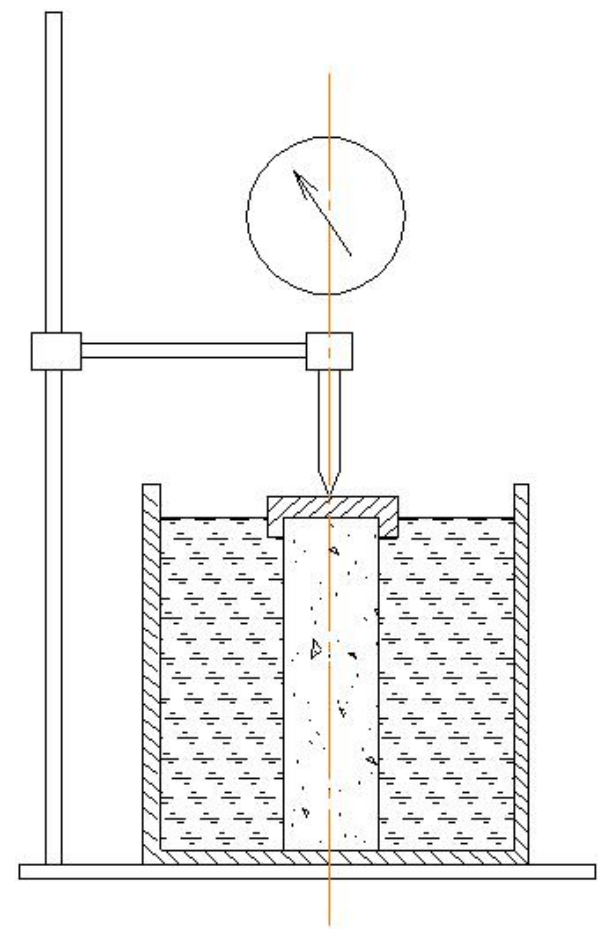

Fig. 1. Measurements of the humidity strains of artificial gypsum stone with mineral additives.

\section{Research data and their discussion}

The research data are given in Fig. 2 and 3 and in Table 1.

Table 1. Maximum humidity strains $\varepsilon$ of the artificial gypsum stone with a different relative content of the mineral additive in the form of ground granulated blast-furnace slag $\mathrm{S}(\mathrm{G}+\mathrm{S})$

\begin{tabular}{|c|c|c|c|c|c|c|c|c|c|}
\hline No & $\begin{array}{c}\text { S/ } \\
(\mathbf{G}+\mathbf{S})\end{array}$ & $\begin{array}{c}\text { W/ } \\
(\mathbf{G}+\mathbf{S})\end{array}$ & \multicolumn{6}{|c|}{ A relative humidity strain of the specimens $\boldsymbol{\varepsilon}_{\boldsymbol{w}}, \mathbf{m} / \mathbf{m}}$. & $\begin{array}{c}\boldsymbol{\varepsilon}_{\text {wmidd }} \\
\mathbf{m} / \mathbf{m}\end{array}$ \\
\hline K & 0 & 0.35 & 0.64020 & 0.78047 & 1.60285 & 1.05040 & 0.91300 & 1.12973 & 1.01937 \\
\hline 1 & 0.09 & 0.32 & 0.59156 & 0.43218 & 0.27623 & & & & 0.43332 \\
\hline 2 & 0.17 & 0.29 & 0.54071 & 0.39653 & 0.54162 & 0.96342 & 0.91690 & 0.78600 & 0.69081 \\
\hline 3 & 0.23 & 0.27 & 1.12251 & 0.72981 & 0.67662 & & & & 0.84298 \\
\hline 4 & 0.29 & 0.25 & 0.75382 & 0.38879 & 0.29888 & & & 0.48050 \\
\hline 5 & 0.33 & 0.23 & 0.35869 & 0.32983 & 0.76449 & & & & 0.34426 \\
\hline
\end{tabular}

Fig. 2 and 3 and Table 1 show that as soon as the specimens are immersed into the water their length starts to elongate immediately due to the humidity strain, i.e. the swelling. The strain was developed during 3 to 5 
hours and after that it attained a maximum value and actually immediately it began to come down.

a)

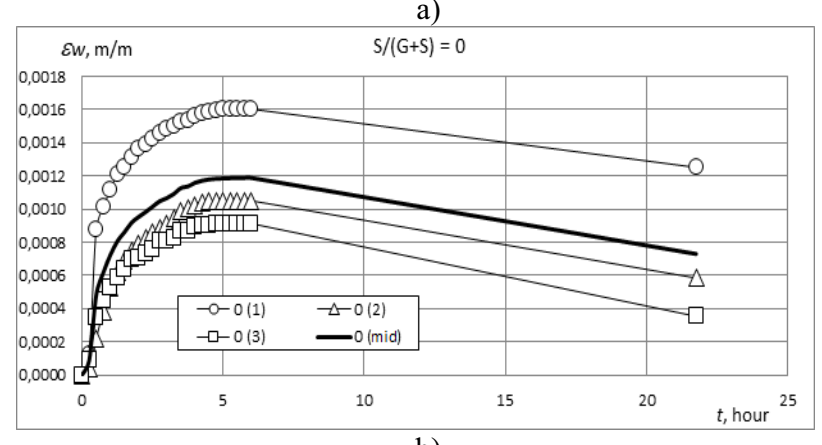

b)



Fig.2. The dependence of the humidity strain $\varepsilon_{w}$ on time $t$ for the artificial gypsum stone with a relative content of the mineral additive, in particular ground granulated blast-furnace slag $\mathrm{S} /(\mathrm{G}+\mathrm{S})$ : $\mathrm{a}-0$ (gypsum stone without additives); $\mathrm{b}$ 0.33 .



Fig.3. The dependence of the humidity strain $\varepsilon_{w}$ on time $t$ for the artificial gypsum stone with a different relative content of the mineral additive, in particular ground granulated blastfurnace slag $\mathrm{S} /(\mathrm{G}+\mathrm{S})$.

It can be seen from Fig. 3 and 4 and Table 1 that the value of humidity strain depends on the content of the mineral additive, i.e. granulated milled blast-furnace slag. A maximum strain is observed for the gypsum stone without mineral additive. A relative strain is decreased with an increase in the slag content. However, this decrease has no linear character; it is wavelike by analogy to the dependences of the strength and water resistance on the slag content.

It can be seen from Fig. 3 and 4 and Table 1 that minimum humidity strains are observed for artificial gypsum stone with a relative slag content of $S /(G+S)$ $0.05-0.1$ and above 0.27 . It agrees with the character of the dependences constructed for the water resistance of the artificial gypsum stone as a function of relative slag content (Fig. 5) and it confirms our assumption that the wedging effect of water concentrated in the contacts between the individual crystals and particles in its structure contributes to a low water resistance of gypsum. Hence, it is reasonable to use the values of humidity strains of artificial gypsum stone as additional indicators of its water resistance.

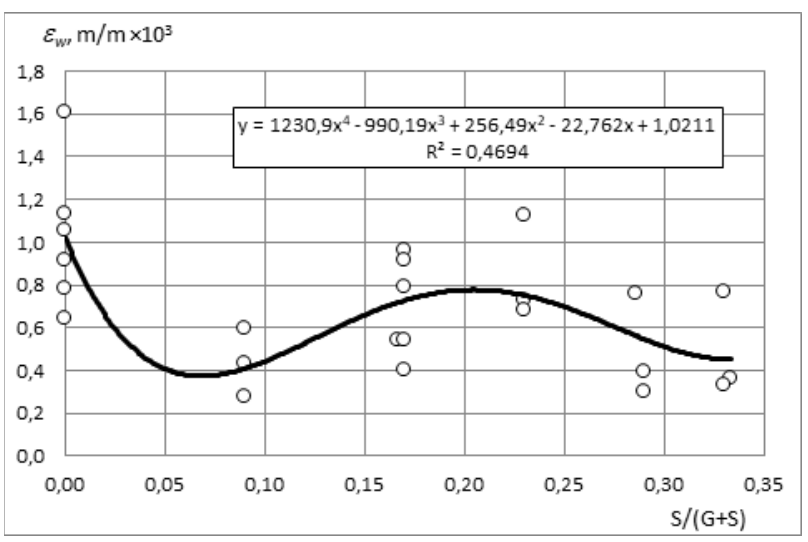

Fig.4. Dependence of a maximum humidity strain $\varepsilon$ of the artificial gypsum stone on a relative content of the mineral additive, in particular ground granulated blast-furnace slag $\mathrm{S} /(\mathrm{G}+\mathrm{S})$.

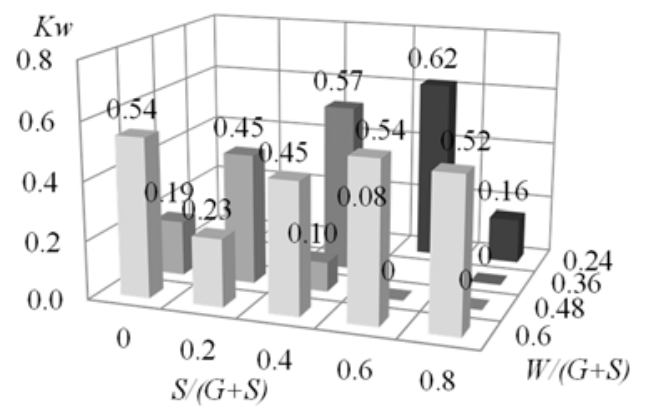

Fig. 5. The dependence of the strength and water resistance ratio $\mathrm{K}_{\mathrm{w}}$ of gypsum-slag stone at the age of 7 days on the content of the filler - slag $\mathrm{S} /(\mathrm{G}+\mathrm{S})$ and water-solid ratio $\mathrm{W} /(\mathrm{G}+\mathrm{S})$ [14].

Therefore, the supplemental addition of the ground granulated blast-furnace slag to gypsum with the mineral additive results in no increase in the strength of artificial gypsum stone and it can even condition a certain reduction of it. However, its strength is increased in the water saturated state and it results in an essential increase in the water resistance, the softening factor in increased in the range of 0.6 to 0.8 and it can attain 1 .

The information given above confirms the theoretical conception that the addition of mineral additives to gypsum results in an increased amount of electroheterogeneous contacts in the artificial stone structure due to the fact that the pores are filled by additive particles. 


\section{Conclusions and recommendations}

The experimental investigations show that as soon as the specimens are immersed into the water their length starts to elongate due to the humidity strain, in particular, the swelling. The strain was developed during 3 to 5 hours and after that it attained a maximum value and actually immediately it began to come down.

It was established that the value of humidity strain depends on the content of the mineral additive, i.e. granulated milled blast-furnace slag. A maximum strain is observed for the gypsum stone without mineral additive. A relative strain is decreased with an increase in the slag content. However, this decrease has no linear character; it is wavelike by analogy to the dependences of the strength and water resistance on the slag content. Minimum humidity strains are observed for the artificial gypsum stone with a relative slag content of $\mathrm{S} /(\mathrm{G}+\mathrm{S})$ 0.05-0.1 and above 0.27.

It confirms our assumption that the wedging effect of water concentrated in the contacts between the individual crystals and the particles in its structure promotes a low water resistance of gypsum. Hence, it is reasonable to use the values of humidity strains of artificial gypsum stone as additional indicators of its water resistance.

\section{References}

1. A.V. Ferronskaja (ed.), Gipsovye materialy $i$ izdelija (Gypsum materials and products). (ASV, Moskow, 2004)

2. M. Sanytsky, H.-B. Fischer, S. Korolko, in 16 Internationale Baustofftagung, BauhausUniversität Weimar, 1, pp. 875-882 (2006)

3. A.A. Plugin, O.A. Plugin, H.-B. Fisher, G.N. Shabanova Increase of gypsum water resistance by mineral additives. Paper presented at the 1 Weimarer Gipstagung, Bauhaus-Universität Weimar, pp. 435-443 (2011)

4. S. Wansom, P. Chintasongkro, \& W. Srijampan, Cement and Concrete Composites, 103, pp. 134148 (2019) https://doi.org/10.1016/j.cemconcomp.2019.04.03 3

5. L.V. Zavadskaya, \& G.I. Berdov, Research Journal of Applied Sciences, Engineering and Technology, 1, pp. 86-93 (2016) http://dx.doi.org/10.19026/rjaset.12.2306

6. H. Sun et al., Cement and Concrete Composites, 112 (2020) https://doi.org/10.1016/j.cemconcomp.2020.10367 4

7. A. D. Egorova, \& K. E. Filippova, IOP Conference Series: Materials Science and Engineering, 687, 022030 (2019) https://doi.org/10.1088/1757-899X/687/2/022030
8. G.N. Pervyshin, et al., Procedia Engineering, 172, pp. 867-874 (2017). doi:10.1016/j.proeng.2017.02.087

9. G. Yakovlev, et al., Procedia Engineering, 108, pp. 13-21. (2015). doi:10.1016/j.proeng.2015.06.195

10. M. Sanytsky, T. Kropyvnytska, H. B. Fischer, \& N. Kondratieva, Chemistry and Chemical Technology, 13(4), pp. 495-502 (2019) https://doi.org/10.23939/chcht13.04.495

11. N. Kondratieva, M. Barre, F. Goutenoire, \& M. Sanytsky, Construction and Building Materials, 149, pp. 535-542 (2017) https://doi.org/10.1016/j.conbuildmat.2017.05.140

12. N. Kondratieva et al., Construction and Building Materials, 235 (2020) https://doi.org/10.1016/j.conbuildmat.2019.117479

13. F. Suárez et al., Construction and Building Materials, 244 (2020) https://doi.org/10.1016/j.conbuildmat.2020.118347

14. A. Plugin A. Iefimenko, O. Borziak, E. Gevorkyan, O. Pluhin, Eastern-European Journal of Enterprise Technologies, 1(6-109), pp. 22-29 (2021). doi:10.15587/1729-4061.2021.224221

15. H. Ivashchyshyn, M. Sanytsky, T. Kropyvnytska, \& B. Rusyn, Eastern-European Journal of Enterprise Technologies, 4(6-100), pp. 39-47 (2019). https://doi.org/10.15587/1729-4061.2019.175472

16. P.V. Krivenko, O. Petropavlovskyi, I. Rudenko, \& O.P. Konstantynovskyi, Materials Science Forum, 968, 13-19 (2019).

https://doi.org/10.4028/www.scientific.net/msf.96 8.13

17. Y. Danchenko et al., MATEC Web of Conferences, 230, 03004 (2018) https://doi.org/10.1051/matecconf/201823003004

18. A.A. Plugin, O.A. Pluhin, O.S. Borziak, \& O.V. Kaliuzhna, Lecture Notes in Civil Engineering, 47 (2020) https://doi.org/10.1007/978-3-030-27011-7_5

19. V. Sopov et al., MATEC Web of Conferences, 116, 01018 (2017) https://doi.org/10.1051/matecconf/201711601018

20. N. Lushnikova, L. Dvorkin, 25 Sustainability of gypsum products as a construction material. In Sustainability of Construction Materials, 2nd edn. (Woodhead Publ., 2016), pp. 643-681. doi:10.1016/B978-0-08-100370-1.00025-1

21. V. Petropavlovskaya, A. Buryanov, T. Novichenkova \& K. Petropavlovskii, IOP Conference Series: Materials Science and Engineering, 365 (2018) https://doi.org/10.1088/1757-899X/365/3/032060

22. Buryanov, A., Petropavlovskaya, V., \& Novichenkova, T. Applied Mechanics and Materials, 467, 91-96 (2014) https://doi.org/10.4028/www.scientific.net/AMM. 467.91 